This is the author's final, peer-reviewed manuscript as accepted for publication. The publisher-formatted version may be available through the publisher's web site or your institution's library.

\title{
Factors associated with early adolescents' anticipated emotional and behavioral responses to ambiguous teases on Facebook
}

Mark A. Barnett, Marcella B. Nichols, Tammy L. Sonnentag, \& Taylor W. Wadian

\section{How to cite this manuscript}

If you make reference to this version of the manuscript, use the following information:

Barnett, M. A., Nichols, M. B., Sonnentag, T. L., \& Wadian, T. W. (2013). Factors associated with early adolescents' anticipated emotional and behavioral responses to ambiguous teases on Facebook. Retrieved from http://krex.ksu.edu

\section{Published Version Information}

Citation: Barnett, M. A., Nichols, M. B., Sonnentag, T. L., \& Wadian, T. W. (2013). Factors associated with early adolescents' anticipated emotional and behavioral responses to ambiguous teases on Facebook. Computers in Human Behavior, 29(6), 2225-2229.

Copyright: (c) 2013 Elsevier Ltd.

Digital Object Identifier (DOI): doi:10.1016/j.chb.2013.05.003

Publisher's Link: http://www.sciencedirect.com/science/article/pii/S0747563213001544

This item was retrieved from the K-State Research Exchange (K-REx), the institutional repository of Kansas State University. K-REx is available at http://krex.ksu.edu 
Factors Associated with Early Adolescents' Anticipated Emotional and Behavioral Responses to Ambiguous Teases on Facebook

Mark A. Barnett, Marcella B. Nichols, Tammy L. Sonnentag, \& Taylor W. Wadian

Kansas State University, 492 Bluemont Hall, 1100 Mid-Campus Dr., Manhattan, KS 66506, USA

Author email addresses: Mark A. Barnett (barn@ksu.edu), Marcella B. Nichols (omegaba1@ksu.edu), Tammy L. Sonnentag (tamson@ksu.edu), \& Taylor W. Wadian (wadiant@ksu.edu)

Address correspondence to Mark A. Barnett, Department of Psychological Sciences, Kansas State University, Manhattan, Kansas 66506, USA; 785-532-0603 (telephone) barn@ksu.edu(email) 


\begin{abstract}
A total of 69 sixth- through eighth-grade students rated their experiences with antisocial and prosocial teases as well as their general attitudes toward teases. Subsequently, the participants read hard copies of four ambiguous teases, one at a time, posted on a simulation of "their" Facebook wall by four different, hypothetical acquaintances. After reading each tease, the participants were asked to complete a questionnaire that assessed their emotional and behavioral response to the tease. Consistent with Weiner's $(1980,1995)$ cognitive (attribution)-emotionaction model of motivated behavior, path analyses revealed that the participants’ negative experiences with teases and negative attitudes toward teases were predictive of a negative emotional response to the ambiguous teases on Facebook which, in turn, was predictive of various negative behavioral responses to the ambiguous teasers. Therefore, consistent with the prior finding of a hostile attribution bias in some children's reactions to ambiguous face-to-face teases (Barnett, Barlett, Livengood, Murphy, \& Brewton, 2010), the early adolescents in the present study with relatively negative experiences with and attitudes toward teases appear to display a hostile attribution bias whereby teases on Facebook with an uncertain intent are viewed as if they were meant to be antagonistic and antisocial.
\end{abstract}

Key words: teasing; hostile attribution bias; peer relations; Facebook 


\section{Introduction}

Teasing is a fascinating and surprisingly complex form of communication. Various contextual, verbal, and nonverbal cues are used by children and adults to distinguish between teases that are meant to be hurtful and antisocial and those that are meant to be affiliative and prosocial (Barnett, Burns, Sanborn, Bartel, \& Wilds, 2004; Keltner, Capps, Kring, Young, \& Heerey, 2001). Although the distinction between antisocial and prosocial teases may be relatively clear to some individuals under some circumstances, the inherent ambiguity of most teases allows the intent of a particular tease to be open to different interpretations (Alberts, 1992; Shapiro, Baumeister, \& Kessler, 1991). Furthermore, differences in personality (Bollmer, Harris, Milich, \& Georgesen, 2003; Georgesen, Harris, Milich, \& Young, 1999), culture (Campos, Keltner, Beck, Gonzaga, \& John, 2007), and personal history with teasing (Bollmer et al., 2003; Lightner, Bollmer, Harris, Milich, \& Scambler, 2000; Scambler, Harris, \& Milich, 1998) may influence an individual's perception of and, ultimately, his/her response to a particular tease.

In an investigation of children's perceptions of and anticipated responses to hypothetical face-to-face teases, Barnett, Barlett, Livengood, Murphy, and Brewton (2010) asked fifth- and sixth-grade students to complete questionnaires assessing their experiences with antisocial and prosocial teases as well as their general attitudes toward teases. Subsequently, the children were asked to read four ambiguous teasing scenarios, one at a time, in which they were to imagine having been teased on four separate occasions by different peers at their school. After considering each tease, the children were asked to rate how much they would feel various emotions (e.g., hurt, sad) and how likely they would be to respond in various ways (e.g., retaliate, complain). In general, children with relatively negative experiences as tease recipients 
and relatively negative attitudes toward teases anticipated (a) responding to the ambiguous teases with more negative emotions and (b) being more likely to respond to the teasers in negative ways than children with more favorable experiences and attitudes. In this prior investigation, the relation between the children's anticipated emotional and behavioral responses to the ambiguous teases was not examined.

Given the growing importance and impact of social networking among 12-15 year olds (Kowalski \& Limber, 2007; Kwan \& Skoric, 2013; Twyman, Saylor, Taylor, \& Comeaux, 2010), the present study sought to determine whether the prior results concerning children's reactions to hypothetical face-to-face teases (Barnett et al., 2010) would be replicated with early adolescents’ anticipated responses to hypothetical teases on the popular social medium of Facebook. Social media, such as Facebook, appears to be an ideal context in which to examine individual differences in adolescents' response to ambiguous teases because the "humorous" comments in such a forum are necessarily "devoid of any verbal (e.g., tone of voice) or nonverbal (e.g., facial expression) cues from the teaser...that individuals typically use to determine if the intent of a tease is hostile or affiliative" (Barnett et al., 2010, p. 57). As with the children in the prior investigation (Barnett et al., 2010), adolescents with relatively negative experiences with and attitudes toward teases were predicted to respond to ambiguous teases on Facebook as if they were meant to be hostile and antisocial (that is, they were expected to display a hostile attribution bias; Crick \& Dodge, 1994, 1996).

Although children's experiences with and attitude toward teases were found to be associated with both their anticipated emotional and behavioral responses to ambiguous teases in the prior study (Barnett et al., 2010), the pattern of relations among these variables was not systematically examined. Weiner's (1980) cognitive (attribution)-emotion-action model of 
motivated behavior proposes a "temporal sequence of attribution-affect-action in which attributions guide our feelings, but emotional reactions provide the motor and direction for behavior" (Weiner, 1980, p. 186). Although Weiner's conceptualization has been applied to a broad range of domains (e.g., achievement, helping behavior; see Weiner, 1995), within the present context his model would suggest that (a) individuals attribute friendly (unfriendly) intent to another's actions or words directed to the self, (b) attributions of friendly (unfriendly) intent elicit a positive (negative) emotional reaction in the self, and (c) a positive (negative) emotional reaction in the self elicits positive (negative) behavioral responses toward the other. In line with Weiner's model, which has gained considerable empirical support (see Weiner, 1995), we expected in the present study that an adolescent's general perception of teasers' antisocial intent (reflected by his/her negative attitude toward teases and long-term negative experience as a recipient of teases) would predict a negative emotional response to ambiguous teases on Facebook which, in turn, would predict negative behavioral responses to the Facebook teasers. As an extension of the prior research (Barnett et al., 2010), path analysis was used to test this model in the present investigation.

\section{Method}

\subsection{Participants}

The participants were 69 sixth- through eighth-grade students (38 females, 29 boys, 2 gender unspecified) from northeast Kansas who ranged in age from 11.7-15.9 years $\left(M_{\text {age }}=12.9\right.$ years; $S D=0.90$ years). The students took part in one of two large group sessions conducted in the school library by a female experimenter and two assistants. 


\subsection{Materials and procedure}

The students were initially presented with descriptions of hurtful, antisocial (labeled Type 1) teases and good-natured, prosocial (labeled Type 2) teases (adapted from Barnett et al., 2004, 2010; see Appendix A). Next, the participants were asked to complete parallel, 3-item "Experiences with Type 1 Teases" (ExpT1; Cronbach's $\alpha=.73)$ and "Experiences with Type 2 Teases" (ExpT2; $\alpha=.63)$ measures developed for use in this study ${ }^{1}$. On these questionnaires, the participants were asked to rate on a 5-point scale, ranging from 1 (strongly disagree) to 5 (strongly agree), how strongly they agree with statements tapping their prior and present experiences with both types of teases (sample item: Ever since I was in first grade, other individuals have teased me in a Type 1 [Type 2] way). Next, the participants completed the 8item Attitude Toward Teasing (ATT) measure used in prior studies (Barnett et al., 2004, 2010; $\alpha=$.83; sample item: Children tease because they want to make other children feel bad). The early adolescents rated each statement on this questionnaire on a 5-point scale ranging from 1 (strongly disagree) to 5 (strongly agree) with higher scores reflecting a more negative attitude toward teasing.

Following their completion of these questionnaires, the participants were given a "Personal Information Page” in which they were asked to indicate their gender and birthdate and to respond to a few questions about their experience (or lack of experience) with Facebook ${ }^{2}$. Finally, the participants read hard copies of four ambiguous teases (see Appendix B), one at a time, posted on a simulation of “their” Facebook wall by four different, hypothetical acquaintances (two males and two females). The gender of the teaser associated with a particular tease and the order in which the four teases were presented were varied across the two group sessions. After reading each tease, the participants completed a questionnaire that asked them to 
rate their emotional and behavioral responses to the tease. With regard to their potential emotional responses, the participants rated on a 5-point scale, ranging from 1 (not at all) to 5 ( $a$ lot), how much they would feel each of four emotions (i.e., hurt, angry, sad, embarrassed) in response to the tease. The participants' average ratings of the four potential emotional responses across the four ambiguous teases were averaged to form a single Negative Emotional Response to Teases (NERT) measure $(\alpha=.89)$ that was used in the analyses reported below. With regard to their potential behavioral responses, the participants rated on a 5-point scale, ranging from 1 (not at all likely) to 5 (very likely), how likely they would be to react to each teaser with each of eight behavioral responses. The potential behavioral reactions to the teasers were written to reflect four categories of response used in the Barnett et al. (2010) investigation: Avoid, Retaliate, Act Friendly, and Complain. Two examples from each category of behavioral response appeared on the questionnaire (see Table 1). Across the four ambiguous teases, the participants' average likelihood rating for each of the eight potential behavioral responses was used in the analyses reported below.

\section{Results}

\subsection{Preliminary analyses}

3.1.1 Use of Facebook. Two-thirds $(n=46)$ of the participants indicated that they have a Facebook account. Of the 67 participants who specified their gender, the proportion of boys and girls who indicated that they have a Facebook account was almost identical (65.5\% and 65.8\%, respectively). Of the participants with an account, approximately half (48.9\%) indicated that they spend 30 minutes or less per day actively engaged in Facebook. At the other extreme, $13.3 \%$ indicated that they spend three hours or more per day actively engaged in Facebook. The 
participants with a Facebook account were older $\left(M_{\text {age }}=13.1\right.$ years; $S D=0.95$ years $)$ than participants without a Facebook account $\left(M_{\text {age }}=12.6\right.$ years; $S D=0.68$ years $), t(66)=2.26$, $p<.05, \eta_{\mathrm{p}}{ }^{2}=.07$. No relation was found between whether or not participants had a Facebook account and any variables of interest in this study.

3.1.2 Gender difference in response to the ambiguous teases. A 2 (gender of participant) x 2 (gender of teaser) ANOVA conducted on the participants’ NERT scores revealed a significant main effect of gender of participant, $F(1,65)=7.94, p<.01, \eta_{\mathrm{p}}{ }^{2}=.11$. Females $(M$ $=2.92, S D=1.10$ ) anticipated having a more negative emotional response to the ambiguous teases than did the males $(M=2.25, S D=0.82)$. A series of 2 (gender of participant) x 2 (gender of teaser) ANOVAs conducted on the females' and males’ ratings of their likelihood of engaging in each of the eight potential behavioral responses to the ambiguous teasers revealed only one significant gender difference. Females $(M=1.36, S D=0.66)$ indicated that they would be less likely to act friendly in response to the ambiguous teases (see Act Friendly \#2 on Table 1) than did the males $(M=1.88, S D=1.10), F(1,65)=5.75, p<.05, \eta_{\mathrm{p}}{ }^{2}=.08$. As in the prior investigation (Barnett et al., 2010), the participants' scores on the emotional and behavioral response measures did not differ significantly when the teaser was described as a boy and when the teaser was described as a girl ${ }^{3}$.

\subsection{Main analyses}

As an extension of prior research (Barnett et al., 2010), the main purpose of this study was to assess the relation between (a) early adolescents' experiences with and attitudes toward teases and (b) their emotional and behavioral responses to ambiguous teases posted on Facebook. More specifically, we sought to determine whether the pattern of relations among scores on these 
variables would be consistent with Weiner's (1980; 1995) cognitive (attribution)-emotion-action model of motivated behavior.

\subsubsection{Correlations with emotional response to the ambiguous teases. The more}

strongly participants agreed that they were the recipient of negative teases and had negative attitudes toward teases, the more negative they anticipated their emotional reaction to be in response to the ambiguous teases, both $r s=.26, p<.05$. In contrast, the participants' ratings of their experiences with positive teases were found to be unrelated to their anticipated emotional response to the ambiguous teases, $r=-.02, p=.88^{4}$.

3.2.2 Correlations with behavioral responses to the ambiguous teasers. As presented in Table 1, the participants' ratings of their (a) experiences with negative and positive teases and (b) attitudes toward teases were generally unrelated to their likelihood of engaging in the various behavioral responses to the ambiguous teasers. Indeed, only two of the 24 correlations were found to be significant and both involved the Complain category of behavioral response. First, the more strongly participants agreed that they were the recipient of positive teases, the less likely they were to anticipate complaining (see Complain \#2, Table 1) in response to the ambiguous teasers. Second, the more negative their attitudes toward teases, the more likely they were to expect to complain (see Complain \#1, Table 1) in response to the ambiguous teasers.

The correlations between the participants’ ratings of their anticipated emotional and behavioral responses to the ambiguous teases yielded a more robust pattern, with five of the eight correlations emerging as statistically significant. As presented in Table 1 , the more negative the participants anticipated their emotional reaction to be in response to the ambiguous teases, the more likely they indicated they would be to respond to the ambiguous teasers by avoiding 
(Avoid \#2), retaliating against (Retaliate \#1), and complaining to them (Complain \#1 and \#2), and the less likely they would be to respond by acting friendly toward them (Act Friendly \#1).

3.2.3 Path analyses. To determine whether the pattern of relations among these variables was consistent with Weiner's $(1980,1995)$ model of motivated behavior, a series of path analyses were conducted. In the first model tested, each participant's rating of his/her (a) experiences with negative and positive teases (i.e., ExpT1 and ExpT2 scores, respectively) and (b) attitudes toward teases (i.e., ATT score) were used as predictors of his/her emotional response to the teases (i.e., NERT score) which, in turn, was used as a predictor of his/her behavioral responses to the teasers, with each of the eight behavioral responses included in a separate analysis. Paralleling the pattern of correlational findings previously described, the path from ExpT2 to NERT in this model was found to be non-significant as were the paths from NERT to three behavioral responses (i.e., Avoid \#1, Retaliate \#2, Act Friendly \#2). Following the procedure described by Tabachnick and Fidell (2007), these non-significant paths were trimmed and the model was tested again. With regard to the revised model (see Figure 1), the data yielded small chi-square values relative to degrees of freedom $(p s>.16)$ and goodness-of-fit indices suggesting that the data fit the model well ${ }^{5}$. The estimations of the structural parameters of the model are also presented in Figure 1. Consistent with the hypothesized effects, the analyses revealed that the participants' experiences with antisocial teases and (negative) attitudes toward teases were predictive of a negative emotional response to the ambiguous teases on Facebook which, in turn, was predictive of five negative behavioral responses to the ambiguous teasers. 


\section{Discussion}

The purpose of the present study was to examine the role of early adolescents' experiences as recipients of teases and general attitudes toward teases in their anticipated emotional and behavioral responses to a series of hypothetical, ambiguous teases presented on Facebook. Correlational and path analyses revealed that (a) the more strongly the participants agreed that they had negative experiences with teases and negative attitudes toward teases, the more negative their anticipated emotional response to the ambiguous teases on Facebook, and (b) the more negative the participants' anticipated emotional response, the more likely they indicated they would be to respond in a negative manner toward the ambiguous teasers. The present results are consistent with the prior finding (Barnett et al., 2010) of a hostile attribution bias (Crick \& Dodge, 1994, 1996; Dodge et al., 2003) in some children’s reactions to ambiguous face-to-face teases. That is, early adolescents in the present study with relatively negative experiences with and attitudes toward teases appear to display a hostile attribution bias whereby teases on Facebook with an uncertain intent are viewed as if they were meant to be antagonistic and antisocial. Furthermore, the path analyses revealed that the pattern of relations among the variables in the present study was consistent with Weiner's $(1980,1995)$ cognitive (attribution)emotion-action model of motivated behavior. Specifically, an adolescent's general perception of teasers' antisocial intent (reflected by his/her negative attitude toward teases and long-term negative experience as a recipient of teases) was found to predict the adolescent's negative emotional response to ambiguous teases on Facebook which, in turn, was found to predict his/her negative behavioral responses to the Facebook teasers.

While cyberbullying is a real and serious threat to the psychological and physical wellbeing of early adolescents (Kowalski \& Limber, 2007; Kwan \& Skoric, 2013; Twyman et 
al., 2010), the present findings suggest that some individuals may have experiences and attitudes that influence them to respond to ambiguous online teases in a more negative manner, emotionally and behaviorally, than other agemates. A young person who responds negatively to an online or face-to-face teaser who has an affiliative or benign intent may unwittingly initiate unpleasant subsequent interactions with that individual (Olweus, 1978; Perry, Kusel, \& Perry, 1988). In one relevant example, Feldman and Dodge (1987) reported that relatively unpopular children were more likely to attribute hostile intent to face-to-face teasers, and to favor more aggressive responses to those teasers, than their more popular counterparts. In general, a young person who responds in an avoidant, unfriendly, complaining, or retaliatory manner to ambiguous teases from peers, whether online or face-to-face, is likely to encourage a negative counter-response from those peers and, in doing so, to perpetuate the young person's belief that others are "out to get me.”

Although not central to the present study, the finding that the girls anticipated experiencing a more negative emotional response to the ambiguous teases on Facebook than did the boys is consistent with the results of a prior investigation of children's reactions to hypothetical face-toface teases (Barnett et al., 2010) as well as other reports of less favorable emotional reactions to teases among females than males (Hopper, Knapp, \& Scott, 1981; Jones, Newman, \& Bautista, 2005; Keltner, Young, Heerey, Oemig, \& Monarch, 1998). As in the Barnett et al. (2010) investigation, the present gender difference in participants’ anticipated emotional response to ambiguous teases was found to be more robust than the gender difference in participants' anticipated behavioral responses to teasers.

In conclusion, early adolescents with relatively negative attitudes toward teases and relatively negative experiences as recipients of teases were found to display a hostile attribution 
bias (Crick \& Dodge, 1994, 1996; Dodge et al., 2003) wherein they expected to respond to ambiguous teases posted on Facebook with negative emotions and, then, negative behaviors that are unlikely to promote good interpersonal relations with peers. Future cross-sectional and longitudinal studies, incorporating more ethnically diverse samples studied in more naturalistic settings, are needed to better understand young people's developing appreciation of the inherent ambiguity of many teases, both online and face-to-face, and the factors that influence individual differences in their tendencies to interpret teases from peers as antisocial or prosocial. Such research may provide additional insight into the maladaptive social cognitions that appear to contribute to some children's and adolescents' negative emotions, negative interpersonal behaviors, and victimization (Crick \& Dodge, 1994, 1996; Dodge \& Frame, 1982; Dodge et al., 2003). 


\section{References}

Alberts, J. K. (1992). An inferential/strategic explanation for the social organization of teases. Journal of Language and Social Psychology, 11, 153-177.

Barnett, M. A., Barlett, N. D., Livengood, J. L., Murphy, D. L., \& Brewton, K. E. (2010). Factors associated with children's anticipated responses to ambiguous teases. Journal of Genetic Psychology, 171, 54-72.

Barnett, M. A., Burns, S. R., Sanborn, F. W., Bartel, J. S., \& Wilds, S. J. (2004). Antisocial and prosocial teasing among children: Perceptions and individual differences. Social Development, 13, 292-310.

Bollmer, J. M., Harris, M. J., Milich, R., \& Georgesen, J. C. (2003). Taking offense: Effects of personality and teasing history on behavioral and emotional reactions to teasing. Journal of Personality, 71, 557-603.

Campos, B., Keltner, D., Beck, J. M., Gonzaga, G. C., \& John, O. P. (2007). Culture and teasing: The relational benefits of reduced desire for positive self-differentiation. Personality and Social Psychology Bulletin, 33, 3-16.

Crick, N. R., \& Dodge, K. A. (1994). A review and reformulation of social informationprocessing mechanisms in children’s social adjustment. Psychological Bulletin, 115, 74-101.

Crick, N. R., \& Dodge, K. A. (1996). Social information-processing mechanisms in reactive and proactive aggression. Child Development, 67, 993-1002.

Dodge, K. A., \& Frame, C. L. (1982). Social cognitive biases and deficits in aggressive boys. Child Development, 53, 620-635. 
Dodge, K. A., Lansford, J. E., Burks, V. S., Bates, J. E., Pettit, G. S., Fontaine, R., \& Price, J. M. (2003). Peer rejection and social information-processing factors in the development of aggressive behavior problems in children. Child Development, 74, 374-393.

Feldman, E., \& Dodge, K. A. (1987). Social information processing and sociometric status: Sex, age, and situational effects. Journal of Abnormal Child Psychology, 15, 211-227.

Georgesen, J. C., Harris, M. J., Milich, R., \& Young, J. (1999). “Just teasing...”: Personality effects on perceptions and life narratives of childhood teasing. Personality and Social Psychology Bulletin, 25, 1254-1267.

Hopper, R., Knapp, M. L., \& Scott, L. (1981). Couples’ personal idioms: Exploring intimate talk. Journal of Communication, 31, 23-33.

Jones, D. C., Newman, J. B., \& Bautista, S. (2005). A three-factor model of teasing: The influence of friendship, gender, and topic on expected emotional reactions to teasing during early adolescence. Social Development, 14, 421-439.

Keltner, D., Capps, L., Kring, A. M., Young, R. C., \& Heerey, E. A. (2001). Just teasing: A conceptual analysis and empirical review. Psychological Bulletin, 127, 229-248.

Keltner, D., Young, R. C., Heerey, E. A., Oemig, C., \& Monarch, N. D. (1998). Teasing in hierarchical and intimate relations. Journal of Personality and Social Psychology, 75, 1231-1247.

Kowalski, R. M., \& Limber, S. P. (2007). Electronic bullying among middle school students. Journal of Adolescent Health, 41, S22-S30.

Kruger, J., Gordon, C. L., \& Kuban, J. (2006). Intentions in teasing: When “just kidding” just isn’t good enough. Journal of Personality and Social Psychology, 90, 412-425. 
Kwan, G. \& Skoric, M. M. (2013). Facebook bullying: An extension of battles in school. Computers in Human Behavior, 29, 16-25.

Lightner, R. M., Bollmer, J. M., Harris, M. J., Milich, R., \& Scambler, D. J. (2000). What do you say to teasers? Parent and child evaluations of responses to teasing. Journal of Applied Developmental Psychology, 21, 403-427.

Olweus, D. (1978). Aggression in the schools: Bullies and whipping boys. Washington, DC: Hemisphere.

Perry, D. G., Kusel, S. J., \& Perry, L. C. (1988). Victims of peer aggression. Developmental Psychology, 24, 807-814.

Scambler, D., Harris, M. J., \& Milich, R. (1998). Sticks and stones: Evaluations of responses to childhood teasing. Social Development, 7, 234-249.

Shapiro, J. P., Baumeister, R. F., \& Kessler, J. W. (1991). A three-component model of children’s teasing: Aggression, humor, and ambiguity. Journal of Social and Clinical Psychology, 10, 459-472.

Tabachnick, B. G., \& Fidell, L. S. (2007). Using multivariate statistics (5 ${ }^{\text {th }}$ ed.). Boston, MA: Allyn \& Bacon.

Twyman, K., Saylor, C., Taylor, L. A., \& Comeaux, C. (2010). Comparing children and adolescents engaged in cyberbullying to matched peers. Cyberpsychology, Behavior, and Social Networking, 13, 195-199.

Weiner, B. (1980). A cognitive (attribution)-emotion-action model of motivated behavior: An analysis of judgments of help-giving. Journal of Personality and Social Psychology, 39, 186-200. 
Weiner, B. (1995). Judgments of responsibility: A foundation for a theory of social conduct. New York: Guilford. 


\section{Footnotes}

${ }^{1}$ The participants also completed parallel, 9-item "Experiences with Type 1 Teases" ( $\alpha=$ .82) and "Experiences with Type 2 Teases" ( $\alpha=$.79) scales adapted from Barnett et al. (2010) in which they were asked to rate on a 5-point scale how often they are currently teased in a Type 1 (Type 2) way by overlapping peer groups (e.g., individuals in your school, individuals who are not your friends). However, these alternative measures of experiences with antisocial and prosocial teases yielded no clear pattern of results and will not be discussed further.

${ }^{2}$ Although a majority of participants indicated that they have a Facebook account (see “Preliminary analyses” section below), the experimenter provided a brief description of the uses and terminology associated with Facebook (e.g., posting on an individual's wall) before proceeding with this portion of the study.

${ }^{3}$ Studies exploring the role of the gender composition of the teaser-target dyad on individuals’ responses to teases have yielded inconsistent results (e.g., Keltner et al., 2001; Kruger, Gordon, \& Kuban, 2006).

${ }^{4}$ This pattern of correlations is consistent with the pattern of correlations found for the children in a prior investigation (Barnett et al., 2010). Specifically, in the prior investigation, the more negative the children's general attitudes toward teases, the more negative they anticipated their emotional reaction to be in response to ambiguous face-to-face teases. In addition, anticipating a heightened negative emotional response to ambiguous teases in the prior investigation was associated more strongly with the children's level of agreement that they were the recipients of antisocial teases than prosocial teases.

${ }^{5}$ Normed fit index (NFI) and comparative fit index (CFI) are two of the most widely used goodness-of-fit indices reported in the psychological literature (Tabachnick \& Fidell, 2007). For 
these goodness-of-fit indices, values close to 1.00 indicate that the data fit the model well. CFI is considered a more robust test of models than NFI for studies with relatively small sample sizes. 
Table 1

Correlations Between Participants' Scores on the Experience with Type 1 and Type 2 Teases Scales, ATT Scale, NERT Measure, and the Ratings of Their Likelihood of Engaging in the Various Behavioral Responses to the Ambiguous Teasers

\section{Behavioral Responses to the Ambiguous Teasers}

Avoid \#1: ignore the teaser and respond to other people who posted on your wall

Avoid \#2: avoid the teaser by posting something on your wall that is unrelated to the tease

Retaliate \#1: post on your wall that you are going to block the teaser from seeing and posting on your Facebook page from that point on

Retaliate \#2: post on your wall something mean (like a Type 1 tease) back to the teaser

Act Friendly \#1: post on your wall something funny (like a Type 2 tease) back to the teaser

Act Friendly \#2: post on your wall that you are going to add the person as a friend on Facebook

Complain \#1: post on your wall something like, “I bet you wouldn't have posted that on my wall if you knew how bad it made me feel”

Complain \#2: post on your wall something like, “those kind of comments aren’t nice and make using Facebook less fun”

$\begin{array}{cccc}\text { ExpT1 } & \text { ExpT2 } & \text { ATT } & \text { NERT } \\ -.17 & .00 & .02 & .07 \\ -.10 & -.17 & .02 & .38^{* *} \\ .19 & -.01 & .23 & .36^{* *} \\ -.02 & -.11 & .04 & .17 \\ -.13 & .08 & -.05 & -.35^{* *} \\ -.08 & -.18 & -.10 & -.06 \\ .13 & -.15 & .30^{*} & .58^{* *} \\ .05 & -.32^{* *} & .21 & .42^{* *}\end{array}$

Note. ExpT1 = Experience with Type 1 Teases Scale; ExpT2 = Experience with Type 2 Teases Scale;

ATT $=($ Negative) Attitude Toward Teases Scale; NERT $=$ Negative Emotional Response to Teases measure

$* p<.05, * * p<.01$ 


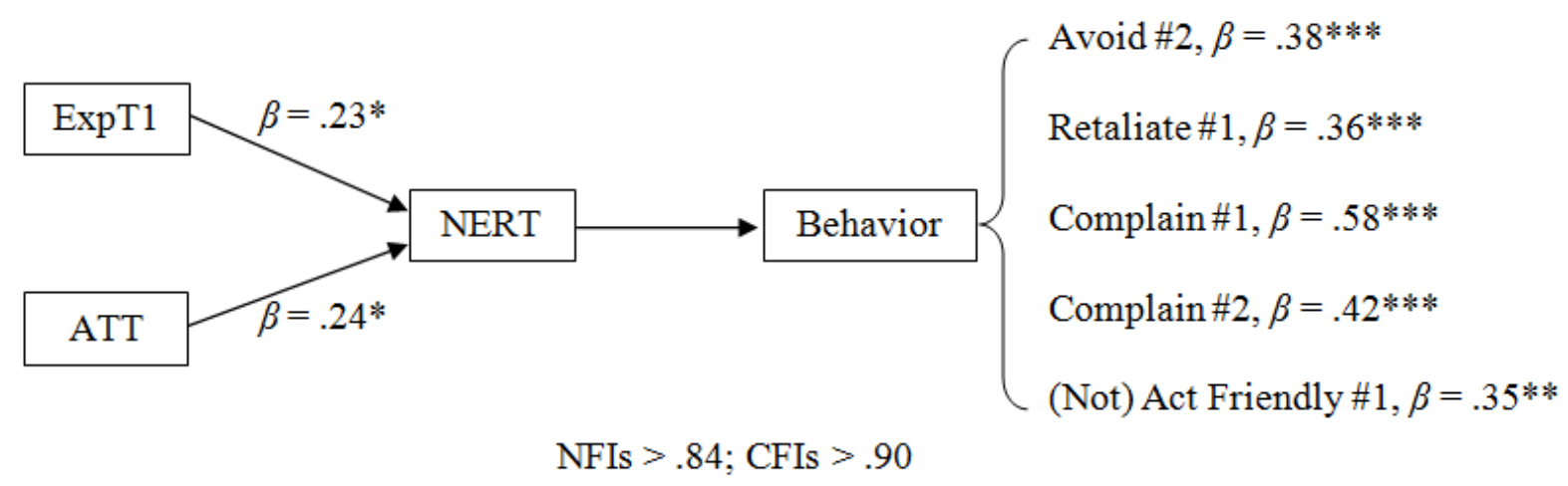

Note. ${ }^{*} p<.05 ; * * p<.01 ; * * * p<.001$.

Figure 1. Results of path analyses examining the predicted relationships among the participants' experiences with antisocial (Type 1) teases (i.e., ExpT1), (negative) attitude toward teases (i.e., ATT), negative emotional response to the teases (i.e., NERT), and five negative behavioral responses to the teasers. 
Appendix A

Descriptions of Type 1 and Type 2 Teases Presented to Participants

In a Type 1 tease, the individual who does the teasing says something about the person who is being teased that purposely hurts the teased person's feelings. In this kind of tease, the individual usually makes fun of the other person in some way, but the person who is being teased doesn't think it's funny and ends up feeling sad or hurt. A lot of times, a Type 1 tease is done in front of other people so the person who is being teased may feel embarrassed, especially if the other people laugh at him or her because of what the individual said.

In a Type 2 tease, the individual who does the teasing says something about the person who is being teased that they can laugh about together. In this kind of tease, the individual usually makes fun of the other person in some way, but the person who is being teased ends up feeling fine knowing that the individual was “just kidding” and didn’t mean to hurt or embarrass him or her in any way. Sometimes, a Type 2 tease even makes the person being teased feel happy because it shows that the individual enjoys "joking around with” and having fun with him or her. 
Appendix B

Wording of Four Ambiguous Teases Posted on Participants' Simulated Facebook Wall

\section{$\underline{\text { Tease } 1}$}

I saw what you wore to school today. Maybe you should try getting dressed with the lights on next time instead of in the dark.

\section{Tease 2}

I saw you spill your drink during lunch today. My baby sister uses a sippy cup for her milk. I'll see if she has an extra one you could borrow.

\section{Tease 3}

I saw you in gym today. Next time, you might try catching the ball with your hands instead of your face.

\section{$\underline{\text { Tease } 4}$}

I saw you when you came into school this morning and took off your winter cap. I guess it was Wild Hair Day today and someone forgot to tell me.

Note. These ambiguous teases were adapted from Barnett et al. (2010). The Facebook wall on which each tease was posted was simulated using a screenshot created with a Microsoft editing program. 


\section{Highlights}

- We examine early adolescents' responses to ambiguous teases on Facebook.

- Females had a more negative emotional response to the teases than did males.

- Negative attitudes toward teases predicted a negative emotional response to teases.

- Negative experiences with teases predicted a negative emotional response to teases.

- A negative emotional response to teases predicted negative behavioral responses. 